\title{
Variação e mudança linguística intrafalante: um estudo de painel sobre a palatalização das oclusivas dentais
}

\author{
Intra-speaker linguistic variation and change: a panel study on palatalization of \\ dental plosives \\ André Wesley Dantas DE AMORIM* \\ Universidade Federal da Paraíba (UFPB) \\ Dermeval DA HORA** \\ Universidade Federal da Paraíba (UFPB) \\ Ingrid Cruz DO NASCIMENTO**** \\ Universidade Federal da Paraíba (UFPB) \\ Pedro Felipe de Lima HENRIQUE**** \\ Universidade Federal da Paraíba (UFPB)
}

\begin{abstract}
RESUMO: A partir de dados em tempo aparente confrontados com dados em tempo real, metodologia de pesquisa chamada por Labov (1994) como estudo de painel, este artigo tem o como objetivo analisar o processo de palatalização das oclusivas dentais /t, d/ do Português Brasileiro (PB) falado em João Pessoa - Paraíba. Utilizando as entrevistas sociolinguísticas do corpus de 1993 e 2015 do Projeto Variação Linguística no Estado da Paraíba - VALPB (HORA, 1993), um estudo longitudinal foi desenvolvido considerando a palatalização na fala de cinco participantes. A principal hipótese é de que o uso da forma palatalizada progrediu na fala dos participantes, após 22 anos. Os resultados sugerem que, no geral, houve um aumento leve, porém estatisticamente significativo no uso da forma africada pelos participantes. Esse achado é consistente com a literatura (BHAT, 1978), que sugere uma tendência das línguas naturais em direção à palatalização.
\end{abstract}

PALAVRAS-CHAVE: Palatalização das oclusivas dentais. Sociolinguística Variacionista. Estudo de painel. Projeto Variação Linguística no Estado da Paraíba.

\footnotetext{
* Mestrando em Linguística pelo Programa de Pós-Graduação em Linguística da Universidade Federal da Paraíba (UFPB). E-mail: amorim_awd@ hotmail.com.

** Doutor em Linguística Aplicada pela Pontifícia Universidade Católica do Rio Grande do Sul. Professor da Universidade Federal da Paraíba. Presidente da Associação de Linguística e Filologia da América Latina (2017-2023). Representante da ALFAL no Comitê Internacional Permanente de Linguistas (CIPL). E-mail: dermeval.dahora@gmail.com

*** Mestranda da Universidade Federal da Paraíba (PROLING) na linha Diversidade e Mudança Linguística. E-mail: ingridcruznascimento@gmail.com

Doutorando em Linguística pela Universidade Federal da Paraíba (UFPB). E-mail: pedrofelipelh@hotmail.com.
} 
ABSTRACT: Using apparent time data compared with real time data, research method called by Labov (1994) as panel study, this article aims at analyzing the process of palatalization of dental plosives /t, $d$ / in the Brazilian Portuguese dialect that is spoken in João Pessoa - Paraíba. Using sociolinguistic interviews from the Projeto Variação Linguística no Estado da ParaíbaVALPB corpus (HORA, 1993), collected in 1993 and 2015, a longitudinal study was conducted considering the palatalization in the speech of five participants. The main hypothesis is that the use of the palatalized variants progressed in relation to the speech of the participants, after 22 years. The results suggest that, in general, although there was a slight increase, it was statistically significant, regarding the use of affricates by the participants. This finding is consistent with the literature (BHAT, 1978), which suggests a tendency of natural languages towards palatalization.

KEYWORDS: Palatalization of dental plosives; Variationist Sociolinguistics; Panel study; Projeto Variação Linguística no Estado da Paraíba

\section{Introdução}

Documentada em mais de 120 línguas naturais (BHAT, 1978), a palatalização é um processo que ocorre quando as consoantes passam a ter uma articulação palatal secundária ou uma mudança no seu primeiro ponto de articulação (KOCHETOV, 2011). Segundo Bhat (1978), as línguas naturais tendem a mudar em direção à palatalização, que geralmente ocorre sob a influência de uma vogal alta ou um glide e tem como principal alvo as consoantes coronais (BATEMAN, 2007).

Um dos tipos de palatalização que ocorre no Português Brasileiro (PB) envolve as oclusivas dentais /t, $\mathrm{d} /$ antes de /i/ em exemplos como po[t]i $>$ po[t $\left.\int\right] \mathrm{i}$, pe[d]ido > pe[dz]ido ou antes de uma vogal anterior média que sofre alteamento para alimentar a regra de palatalização, a exemplo de $\left.\operatorname{po}[\mathrm{t}] \mathrm{e}>\operatorname{po}[\mathrm{ti}]>\operatorname{po[t} \int \mathrm{i}\right], \operatorname{po}[\mathrm{d}] \mathrm{e}>\operatorname{po}[\mathrm{di}]>\operatorname{po}[\mathrm{d} z \mathrm{i}]$. Vale salientar que tanto a manutenção da oclusiva dental quanto sua forma palatalizada são encontradas no Brasil, com predominância da forma palatalizada, pelos menos na maioria das capitais (ver seção 3), como indicam os resultados obtidos pelo Atlas Linguístico do Brasil - AliB (CARDOSO et al., 2014).

Neste artigo, será analisado o uso das oclusivas dentais no falar pessoense, a partir da análise de dados de entrevistas sociolinguísticas com cinco participantes do Projeto Variação Linguística no Estado da Paraíba - VALPB (HORA, 1993), coletados 
tanto em 1993, quanto em 2015. O principal objetivo é, pois, verificar se a forma palatalizada das oclusivas dentais teve seu uso ampliado por parte dos cinco participantes ou se permaneceu estável após uma geração.

O VALPB foi implementado em 1993 e teve como um dos objetivos principais traçar o perfil linguístico do falante paraibano. A estratificação social dos sessenta informantes considerou três variáveis: sexo, faixa etária e anos de escolarização. A partir dos dados levantados, inúmeros trabalhos foram realizados, considerando diferentes aspectos linguísticos - fonologia, sintaxe, discurso, entre outros.

Após vinte e dois anos da primeira coleta, foi feito um estudo de recontato com os informantes da primeira fase do VALPB, e foram localizados dez informantes, dos quais apenas sete aceitaram submeter-se a uma nova entrevista e, desses, cinco fazem parte deste trabalho. A partir das novas entrevistas sociolinguísticas, as taxas de ocorrência da variante palatalizada em cada informante foram comparadas levando em consideração o ano de coleta da amostra (ver seção 4).

Com relação aos resultados esperados, considerando principalmente os estudos de Hora (1995), Andrade (2008) e Henrique \& Hora (2012), a hipótese principal é que a taxa de produção da palatalização das oclusivas dentais progrediu na fala dos cinco participantes, isto é, espera-se que o uso da africada tenha aumentado.

Este artigo está estruturado em cinco seções, a saber: a primeira traz uma revisão sintética da sociolinguística laboviana acerca de seu olhar sobre estudo em tempo real; a segunda apresenta uma revisão dos trabalhos focados na palatalização das oclusivas dentais; a terceira esboça a metodologia utilizada para esse estudo, incluindo o tratamento estatístico para testar a hipótese levantada; a quarta traz os resultados obtidos e a discussão que os envolve; a quinta e última, à guisa de considerações finais, aponta as limitações da pesquisa e as possíveis expansões que seus resultados sugerem para o trabalho com análises de mudança em tempo real.

\section{A Sociolinguística Laboviana e os estudos de variação em tempo real}

Na Sociolinguística Variacionista, a fim de investigar o processo de variação e mudança linguística, o pesquisador pode optar por pelo menos duas metodologias: tempo aparente e tempo real (LABOV, 1994, p.63). Para Labov, no estudo em tempo 
aparente, o comportamento linguístico é analisado partir de uma gradação etária, ou seja, em um dado recorte de tempo, os dados de falantes de diferentes gerações são utilizados para prever a mudança linguística. Sabendo que a fala do idoso reflete usos linguísticos mais antigos e que os jovens costumam utilizar inovações linguísticas, é possível analisar a implementação de uma mudança. Segundo Schilling-Estes (2005), esse método tem provocado questionamentos quanto a sua generalização, apesar de sua robustez.

A pesquisa em tempo real é caracterizada por um estudo longitudinal, onde se investiga o comportamento linguístico a partir de pelo menos dois recortes temporais (LABOV, 1994, p. 63). Ela pode ser conduzida de duas maneiras: estudo de tendência, coleta e análise de dados da gravação de pessoas da comunidade em momentos distintos e estudo de painel, coleta e análise de dados da gravação dos mesmos indivíduos em diferentes momentos de suas vidas, talvez pelo fato de a regra de palatalização ser a mais inovadora na comunidade em pauta.

Apesar de ambas as metodologias de estudo em tempo real utilizarem uma perspectiva diacrônica, sua principal diferença é que, em tendência, um estudo em tempo aparente é replicado, seguindo a mesma metodologia, estratificação, e na mesma comunidade de fala. Portanto, o estudo de tendência não utiliza os mesmos participantes nas duas amostras, mas tenta buscar falantes que têm o mesmo perfil que os do corpus a ser comparado. Por outro lado, o estudo de painel realiza uma pesquisa de recontato, ou seja, o pesquisador volta à comunidade de fala já pesquisada e investiga a fala dos mesmos participantes que já foram analisados em uma outra sincronia. Segundo Labov (1994, p. 63), “a combinação de evidências no tempo aparente e no tempo real é o método básico para o estudo da mudança em progresso". Apesar de suas diferenças, o uso de ambas as metodologias parece ser a forma mais segura de investigar o processo de variação e mudança linguística em uma dada comunidade.

Na comunidade de fala de João Pessoa - Paraíba, lugar em que se situa a pesquisa aqui desenvolvida, três estudos em tempo aparente já foram conduzidos, ambos utilizando o corpus de 1993 do VALPB (HORA, 1997; ANDRADE, 2008; HENRIQUE \& HORA, 2012). Todos revelam que a taxa geral de aplicação da regra parece ser baixa nessa comunidade, sendo de 7,4\%, segundo Hora (1997), de 7,5\%, segundo Andrade (2008), e de 10,48\%, segundo Henrique e Hora (2012). Esses achados 
mostram que, diferentemente da maioria dos dialetos do Português falado no Brasil, a taxa de palatalização das oclusivas dentais em João Pessoa é relativamente baixa. Portanto, esses estudos sugerem que João Pessoa faz parte de um grupo minoritário dos dialetos do PB cujos falantes raramente palatalizam na fala coloquial.

\section{A palatalização das oclusivas dentais no PB}

No PB, em alguns dialetos, as consoantes oclusivas /t/ e /d/ tendem a palatalizarse antes da vogal alta [i] ou do glide [y], passando a ser produzidas como [t] e [dz], resultado de um processo de assimilação regressiva (CAMARA JR., 1976, p. 56), como em (1).

(1)

$$
\begin{aligned}
& \text { ‘tipo' }[\mathrm{t}] \text { ipo } \sim[\mathrm{t} f] \text { ipo } \quad \text { 'tecido' }[\mathrm{t}] \text { ecido }>[\mathrm{t}] \text { icido } \sim[\mathrm{t} f] \text { icido } \\
& \text { 'catita' ca[ti]ta } \left.\sim \text { ca[tif]ita 'categoria' ca[t] egoria }>\text { ca[t]igoria } \sim \text { ca[t } \int\right] \text { igoria } \\
& \text { 'poti' po[t]i } \sim \text { po[t }] \text { i 'pote' po[t]e }>\text { po[t]i } \sim \text { po[t }] \mathrm{i} \\
& \text { 'dito' }[\mathrm{d}] \text { ito } \sim[\mathrm{d} 3] \text { ito } \quad \text { 'pedi' pe[d]i } \sim \operatorname{pe}\left[\mathrm{d}_{3}\right] \mathrm{i} \\
& \text { 'onde' on }[\mathrm{d}] \mathrm{e}>\text { on[d]i } \sim \text { on[dz]i 'pedido' pe[d]ido } \sim \text { pe[dz]ido } \\
& \text { 'hóstia' hos[t]ia } \sim \text { hos[tf]ia 'índio' ín[d]io } \sim \text { ín[dz]io }
\end{aligned}
$$

Esse fenômeno é muito comum em grande parte das regiões do Brasil, e já foi objeto de estudo de vários pesquisadores, dentre eles Lopez (1979), que analisou o dialeto carioca; Bisol (1985), que utilizou dados de fala coletados em comunidades gaúchas; também, no Rio Grande do Sul, outros trabalhos foram desenvolvidos mais recentemente, tais como: Almeida (2000), Kamianecky (2002), Pires (2003), Matté, 2009), Dutra (2007), Battisti \& Rosa (2007) e Battisti \& Filho (2015). Há, ainda, o estudo de Hora (1990), que analisou o fenômeno na comunidade de Alagoinhas (BA); Santos (1996), que investigou a comunidade de Maceió (AL); Pagotto (2001), que pesquisou a comunidade de Florianópolis (PE); e Silva Filho (2018), que estudou o 
dialeto de Recife (PE). Todos esses trabalhos citados são de cunho variacionista, seguindo a perspectiva laboviana.

Uma análise desses estudos citados, sem detalhar seus resultados em que são consideradas as restrições estruturais e sociais, mostra que a realização da oclusiva dental está circunscrita ao nordeste brasileiro, mas que ela também é encontrada em Santa Catarina e no Rio Grande do Sul. Para maiores detalhes, sugere-se que sejam considerados os trabalhos mencionados, muitos deles teses e dissertações.

Utilizando o Projeto da Norma Urbana Culta (NURC), Abaurre e Pagotto (2002) analisam a ocorrência da palatalização das oclusivas dentais em cinco capitais brasileiras (Porto Alegre, Rio de Janeiro, São Paulo, Salvador e Recife). Os autores concluem que as capitais em que a regra se aplica majoritariamente são Rio de Janeiro e Salvador, sendo Recife a de menor aplicação, como se pode observar na Tabela 1.

Tabela 1 - Distribuição da palatalização nas capitais do Projeto NURC

\begin{tabular}{lccc}
\hline Cidades & Ocorrências & $\%$ & Peso Relativo \\
\hline Recife & $66 / 949$ & 7 & .02 \\
Salvador & $642 / 745$ & 85 & .73 \\
Rio de Janeiro & $841 / 844$ & 100 & .99 \\
São Paulo & $543 / 747$ & 40 & .48 \\
Porto Alegre & $304 / 758$ & 59 & .18 \\
\hline
\end{tabular}

Fonte: Abaurre e Pagotto (2002)

Sob outra perspectiva, com foco na Dialectologia, o Atlas Linguístico do Brasil ALiB (CARDOSO et al., 2014), apresenta resultados de todas as capitais brasileiras, mapeando a distribuição do uso das formas palatalizadas e não palatalizadas, como mostra a Figura 1. 
Figura 1 - Carta do Atlas Linguístico do Brasil sobre a distribuição da realização das palatais antes de $[\mathbf{i}]</ \mathrm{i} /$ e $[\mathrm{i}]</ \mathrm{E}, \mathrm{I} /$

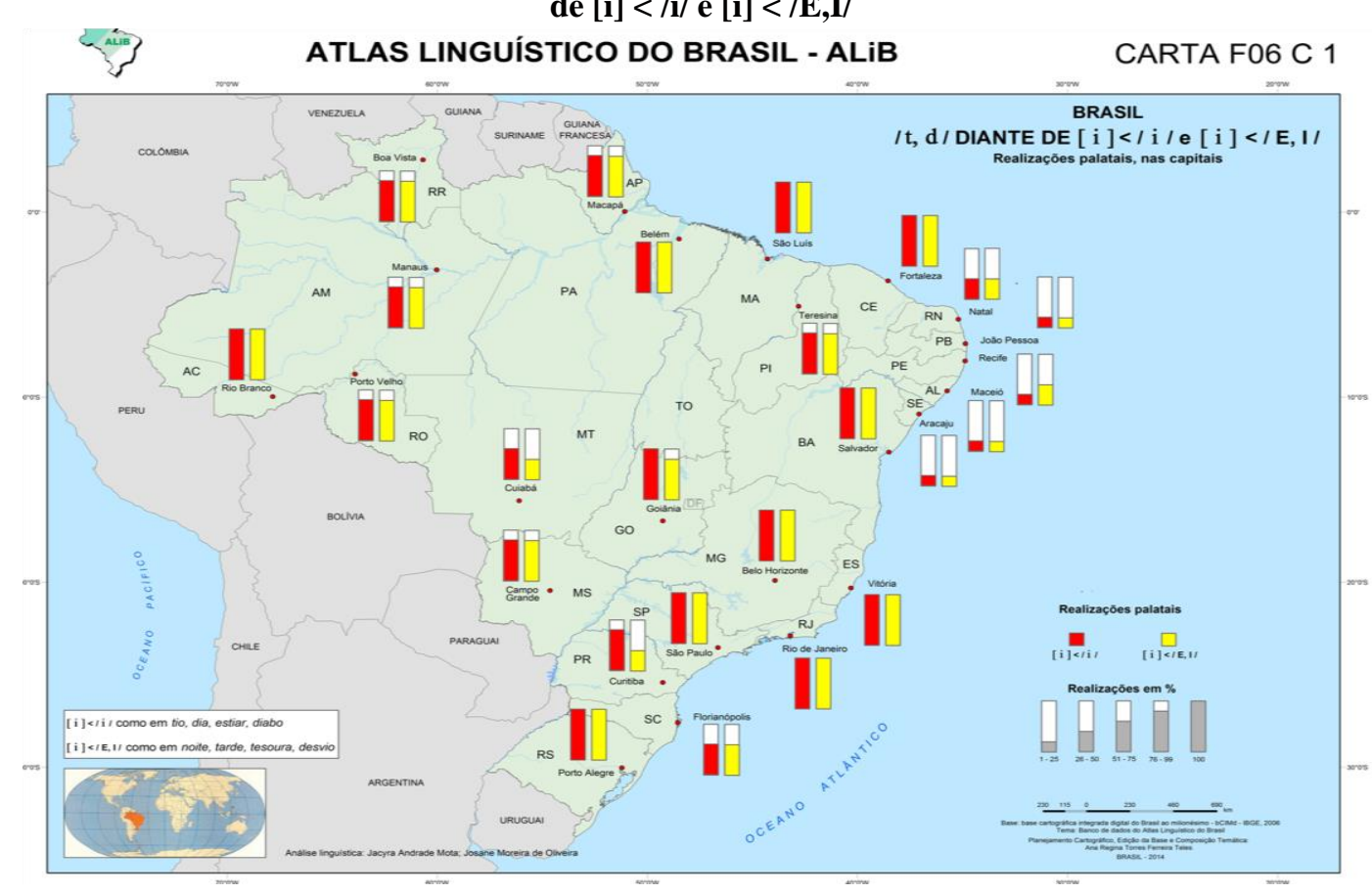

Fonte: Cardoso et al. (2014).

A partir da observação da Figura 1, percebe-se que a forma palatalizada é a tendência nacional, seja a oclusiva dental seguida da vogal alta ou de uma média que se eleva, com distribuição categórica em algumas capitais: no Norte, Rio Branco e Belém; no Nordeste, em São Luís, Fortaleza e Salvador; no Centro-Oeste, apenas Goiânia; no Sudeste, em todas as capitais; no Sul, em Porto Alegre. No caso do Rio Grande do Sul, embora esse estudo demonstre que a forma palatalizada é categórica em sua capital, o mesmo não se pode afirmar a partir dos estudos variacionistas realizados no interior do estado, onde o uso da oclusiva dental é bastante produtivo.

Considerando a comunidade de fala de João Pessoa, comunidade que serviu de base para a pesquisa aqui desenvolvida, três estudos foram desenvolvidos a partir do corpus coletado em 1993 pelo Projeto Variação Linguística no estado da Paraíba VALPB (HORA, 1993): Hora (1997), Andrade (2008) e Henrique e Hora (2012). No que se refere à taxa geral de aplicação da regra de palatalização, os resultados indicam pouca produtividade, sendo 7,4\%, segundo Hora (1997); 7,5\%, segundo Andrade (2008); e 10,48\%, segundo Henrique e Hora (2012). Restrições sociais, como sexo e faixa etária, e estruturais, como contexto precedente, tonicidade e vozeamento, condicionaram a palatalização das oclusivas em João Pessoa segundo esses estudos. 
O fato de a forma palatalizada ser registrada como uma tendência natural das línguas, influenciada, principalmente, pelo seu contexto fonológico seguinte com o espraiamento do traço coronal da vogal [i] ou do glide [y], foi o que motivou esse estudo a partir de dados em tempo real. Espera-se que seja possível traçar um panorama mais específico sobre possíveis mudanças em taxas de produção de indivíduo para indivíduo e dentro de seu próprio uso no decorrer de um intervalo de 20 anos, o que pode oferecer pistas pontuais para que caminho segue o processo de palatalização na capital paraibana.

\section{Metodologia}

Para o desenvolvimento de uma pesquisa em tempo real na perspectiva de painel, consoante Labov (1994), é necessário que o desenho experimental do estudo seja o mesmo para ambas as coletas. Para a condução da presente pesquisa, buscou-se recontactar os 60 participantes do corpus original do VALPB. Desses, apenas 5 participaram desta pesquisa. Portanto, todos os cinco participantes foram gravados tanto em 1993, quanto em 2015.

Vários problemas impediram a localização dos participantes, tais como endereço e telefones desatualizados, falecimentos, mudanças de cidade, entre outros. Entretanto, 5 deles foram encontrados e fizeram parte da amostra de recontato. Sua estratificação atual, consoante a estrutura proposta durante a primeira coleta, pode ser observada no Quadro 1.

Quadro $1^{1}$ - Estratificação dos informantes da amostra de recontato

\begin{tabular}{|c|c|c|c|c|c|}
\hline Sexo & \multicolumn{2}{|c|}{ Masculino } & \multicolumn{2}{c|}{ Feminino } \\
\hline Idade & \multicolumn{2}{|c|}{$26-49$} & \multicolumn{2}{c|}{+ de 49} \\
\hline Escolaridade & \multicolumn{2}{|c|}{ Superior } & Fundamental Incompleto & Analfabeto \\
\hline Informante & HBS & VLF & MLTS & MJCO & MJS \\
\hline
\end{tabular}

Fonte: Adaptado de Amorim et al. (2019).

\footnotetext{
${ }^{1}$ A metodologia da coleta desses dados foi exposta por Amorim et al. (2019).

Revista Moara, n. 54, ago-dez 2019 ISSN: 0104-0944

Recebido em 10/11/2019

Avaliado em 25/11/2019
} 
Conforme o Quadro 1, foram recontactados dois informantes do sexo masculino e três do sexo feminino, dentre os quais três têm faixa etária de 26-49 e dois acima de 49. Como o recontato ocorreu após aproximadamente 22 anos da primeira amostra do VALPB, não há informantes com a faixa etária abaixo de 26 anos. No presente corpus, dois informantes têm nível de escolaridade superior, enquanto uma é analfabeta, e os demais têm apenas o ensino fundamental incompleto. $\mathrm{O}$ quadro 2 detalha, a partir de uma breve biografia, aspectos educacionais, de trabalho e moradia de cada um dos informantes em ambos os períodos de coleta (1993 e 2015).

Quadro 2 - Breve bibliografia dos informantes em cada período de coleta

\begin{tabular}{|c|c|c|}
\hline Informante & 1993 & 2015 \\
\hline $\begin{array}{l}\text { HBS - Homem, } 38 \\
\text { anos, nascido em João } \\
\text { Pessoa e tem pais } \\
\text { pessoenses. }\end{array}$ & $\begin{array}{l}\text { Tinha } 15 \text { anos, morava em um bairro de } \\
\text { classe média baixa, cursava o ensino médio e } \\
\text { não trabalhava. }\end{array}$ & $\begin{array}{l}\text { Havia se mudado para um } \\
\text { bairro de classe média alta, } \\
\text { concluído o ensino superior e } \\
\text { trabalhava como professor de } \\
\text { uma cidade próxima da capital. }\end{array}$ \\
\hline $\begin{array}{l}\text { VLF - Homem, } 41 \\
\text { anos, nascido em João } \\
\text { Pessoa e tem pais } \\
\text { pessoenses. }\end{array}$ & $\begin{array}{l}\text { Tinha } 15 \text { anos, já havia morado em alguns } \\
\text { bairros da cidade, cursava o ensino médio na } \\
\text { antiga Escola Técnica (atual IFPB) e teatro, o } \\
\text { que lhe possibilitava o contato com muitas } \\
\text { pessoas de outros estados. }\end{array}$ & $\begin{array}{l}\text { Havia concluído o ensino } \\
\text { médio, viajado por alguns } \\
\text { estados do país e trabalhava } \\
\text { com produção de eventos. }\end{array}$ \\
\hline $\begin{array}{l}\text { MLTS - Mulher, } 47 \\
\text { anos, nascida em João } \\
\text { Pessoa e com pais } \\
\text { pessoenses. }\end{array}$ & $\begin{array}{l}\text { Tinha } 25 \text { anos, não havia terminado o ensino } \\
\text { fundamental, trabalhava como camelô, } \\
\text { morava em um bairro de classe baixa e } \\
\text { viajava com frequência para Recife - PE. }\end{array}$ & $\begin{array}{l}\text { Havia terminado o ensino } \\
\text { fundamental, mudado para } \\
\text { outro bairro de classe baixa e } \\
\text { trabalhava como garçonete em } \\
\text { um bairro nobre da cidade. }\end{array}$ \\
\hline $\begin{array}{l}\text { MJCO - Mulher, } 64 \\
\text { anos, nascida em João } \\
\text { Pessoa e com pais } \\
\text { pessoenses. }\end{array}$ & $\begin{array}{l}\text { Tinha } 42 \text { anos, trabalhava como doméstica e } \\
\text { tinha estudado até o } 4^{\circ} \text { ano. Embora nunca } \\
\text { houvesse mudado de bairro ou saído da } \\
\text { cidade, mantinha contato frequente com } \\
\text { alguns de seus parentes que moravam na } \\
\text { região Sudeste. }\end{array}$ & $\begin{array}{lrr}\text { A situação } & \text { de educação, } \\
\text { trabalho e } & \text { moradia da } \\
\text { informante } & \text { permaneceu } & \text { a } \\
\text { mesma. } & & \end{array}$ \\
\hline $\begin{array}{l}\text { MJS - Mulher, } 77 \text { anos, } \\
\text { nascida em João } \\
\text { Pessoa, tem pais } \\
\text { nascidos no interior do } \\
\text { estado. }\end{array}$ & $\begin{array}{l}\text { Tinha } 55 \text { anos, morava em um bairro de } \\
\text { periferia da cidade, não era escolarizada, } \\
\text { trabalhava como auxiliar de serviços gerais e } \\
\text { nunca tinha saído do estado, porém algumas } \\
\text { pessoas de sua família haviam se mudado } \\
\text { para a região Sudeste do país. }\end{array}$ & $\begin{array}{l}\text { Aposentou-se e a sua situação } \\
\text { educacional e de moradia } \\
\text { permaneceu a mesma. }\end{array}$ \\
\hline
\end{tabular}

Fonte: Adaptado de Amorim et al. (2019. 
A respeito do instrumento de coleta de dados, foi utilizada uma entrevista sociolinguística semi-estruturada, organizada com base na utilizada em 1993. Com duração total entre 35 a 55 minutos, contemplou os seguintes tópicos: (a) bairro; (b) infância; (c) família; (d) lazer; e (e) cidade de João Pessoa. Os tópicos visam a obter informações sobre aspectos da vida do informante, tais como sobre a escolaridade, a rede social de que fez/faz parte, as características socioeconômicas, o enraizamento e o grau de mobilidade no(s) bairro(s) onde vive/viveu. As gravações foram feitas em um único encontro com cada informante, havendo um breve intervalo entre cada uma delas, sendo todas realizadas usando o gravador Tascam DR-2d. Todas as gravações foram conduzidas em João Pessoa, na casa dos informantes.

Os dados das gravações foram analisados e transcritos de maneira impressionista no ELAN (HELLWIG; GEERTS, 2019), e exportados para uma planilha “.csv”. Em seguida, o tratamento dos dados, as análises descritiva e inferencial e a elaboração dos gráficos foram conduzidos utilizando a linguagem R (R CORE TEAM, 2019), por meio do ambiente RStudio (RSTUDIO TEAM, 2018). Foram consideradas, para as testagens de hipóteses, as seguintes variáveis dependente e independentes:

Quadro 3 - Variáveis utilizadas

\begin{tabular}{|l|l|l|}
\cline { 2 - 3 } \multicolumn{1}{c|}{} & Variável & Níveis \\
\hline Variável dependente & Ocorrência & Palatalização; Não-Palatalização \\
\hline Variáveis independentes & Época da coleta & Corpus 1993; Corpus 2015 \\
\cline { 2 - 3 } & Informante & HBS; VLF; MLTC; MJCO; MJS \\
\hline
\end{tabular}

\section{Resultados e discussão}

Em relação aos cinco participantes da pesquisa, foi observado, no intervalo de 22 anos entre as duas coletas, um leve aumento no uso da palatalização das oclusivas dentais /t/ e /d/ diante de [i]. O número de observações total foi de 1823, para as gravações de 1993, e de 1133, para as gravações de 2015. O Gráfico 1 de barras abaixo 
apresenta as proporções da ocorrência de palatalização de acordo com a amostra. Notase uma pequena diferença de $2,7 \%$ entre as duas amostras.

Do ponto de vista descritivo, de maneira geral, o uso da palatalização parece não ter aumentado significativamente em 22 anos. No entanto, o teste de qui-quadrado $\left(\chi^{2}\right.$ (1) $=19,28, \mathrm{n}=2956, p<0,05)$ fornece evidências estatísticas de que essa mudança, mesmo pequena, foi significativa. Nesse sentido, é mais provável que o aumento no uso da palatalização indicado pelo Gráfico 1 não seja fruto do acaso, mas de uma possível mudança no comportamento linguístico dos participantes em geral. Portanto, a proporção de ocorrência de palatalização referente aos dados dos cinco participantes segue o previsto pela literatura, de que as línguas tendem a apresentar uma tendência natural para a palatalização. Mesmo nessa proporção, o uso da forma palatalizada progrediu de maneira geral.

\section{Gráfico 1 - Proporção do uso da forma palatalizada durante entrevista sociolinguística de cinco} participantes de João Pessoa, de acordo com Amostra

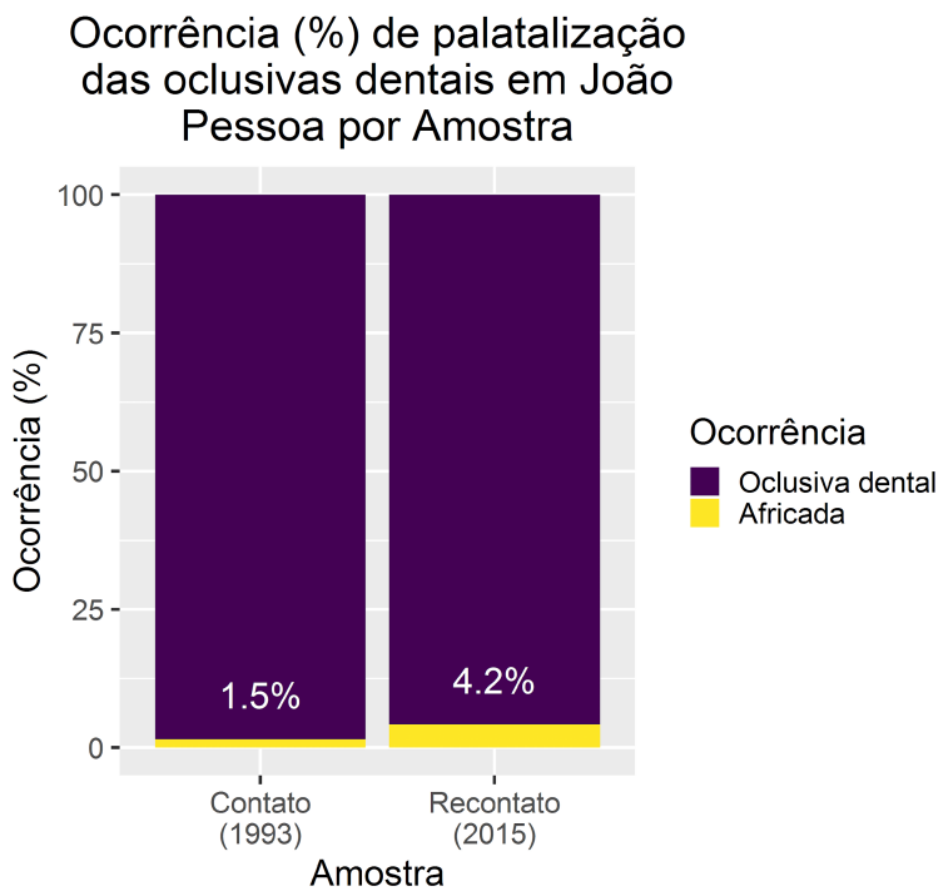

Fonte: elaborado pelos autores

Ao analisar a progressão da palatalização, mais detalhadamente, é possível observar que, com exceção de um participante, todos os outros passaram a palatalizar com mais frequência. O Gráfico 2 mostra a proporção de aplicação da regra de acordo 
com a amostra e com os participantes. No painel esquerdo, encontram-se as proporções relativas às gravações conduzidas em 1993; do lado direito, as proporções relativas às gravações de 2015. Cada sigla corresponde a um dos 5 participantes. O total de observações para cada participante foi de, respectivamente, 718, 628, 344, 542, e 724. O Gráfico mostra uma diferença evidente no uso da palatalização em relação aos participantes na coleta de 1993. Note que, no painel esquerdo, todos palatalizaram em menos de $1 \%$ das ocorrências de /t/ e /d/, com exceção de MLTS, que palatalizou em 6,4\%. Essa participante, portanto, apresentou um comportamento linguístico atípico em comparação com os outros. Nas coletas de 2015, diferentemente, a proporção de todos os participantes foi mais próxima.

Gráfico 2 - Proporção do uso da forma palatalizada durante entrevista sociolinguística de cinco participantes de João Pessoa, de acordo com Amostra e Participante

\section{Ocorrência (\%) de palatalização das oclusivas dentais em João Pessoa por Amostra e Participante}

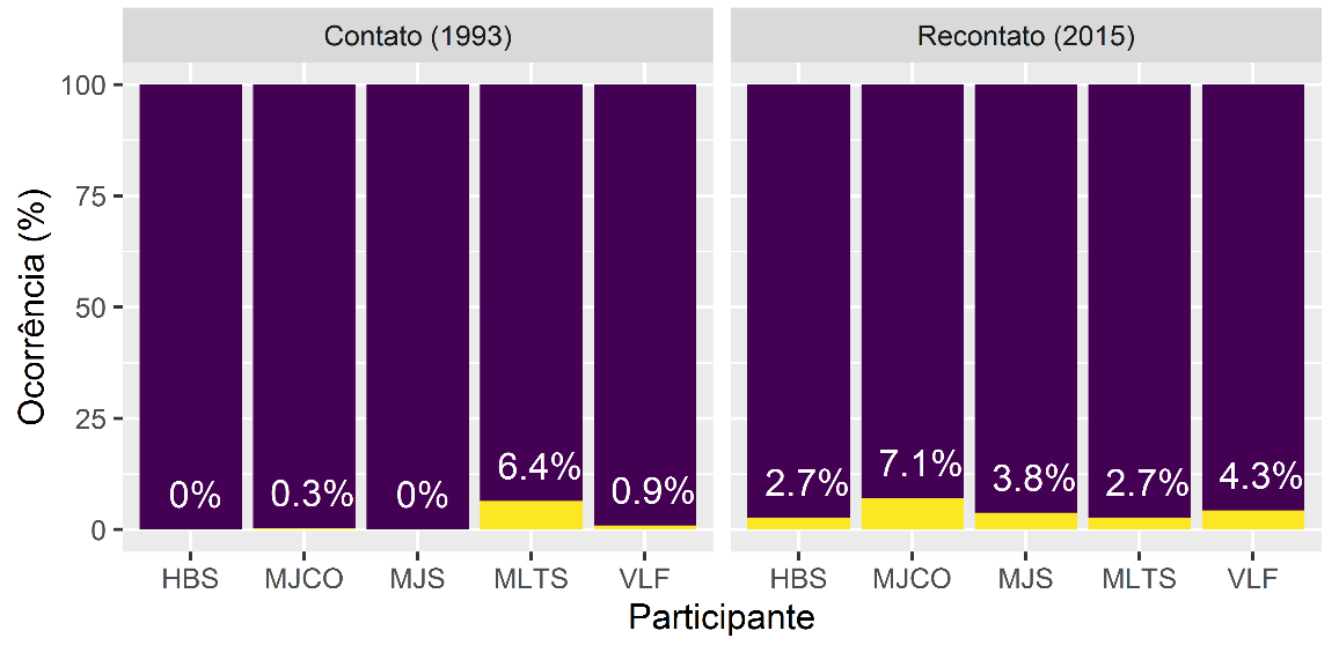

Ocorrência $\square$ Oclusiva dental $\square$ Africada

Fonte: Elaborado pelos autores

Ao mensurar globalmente a associação entre a amostra e a ocorrência da palatalização, o teste de qui-quadrado indica que houve uma significativa diferença no padrão linguístico dos participantes na coleta de $1993\left(\chi^{2}(4)=71.53, \mathrm{n}=1823, p=\right.$ 0,09). Entretanto, em 2015, parece não haver mais uma diferença significativa no uso de palatalização entre os 5 participantes $\left(\chi^{2}(4)=7.83, \mathrm{n}=1133, p=0,09\right)$. 
Observe ainda que, como pode ser visto no Gráfico 2, a participante MLTS, após 22 anos, parece ter acomodado a sua fala em relação a como a comunidade pessoense mais parece falar, ou seja, ela passou a usar a palatalização com menos frequência. Após um pouco mais de duas décadas, sua proporção de uso da palatalização reduziu e passou a ficar bem mais próxima do que era esperado em 93 (2,3\%).

No geral, em 2015, o comportamento dos participantes foi mais homogêneo, pois não houve uma diferença estatisticamente significativa entre eles. Isso implica que a distribuição da frequência da palatalização na fala de todos os cinco participantes parece vir da mesma população. Além disso, note que, com exceção de MLTS, o uso da forma africada progrediu em todos eles.

\section{Considerações finais}

O processo de palatalização das oclusivas dentais, como se pode observar, é bastante produtivo no $\mathrm{PB}$, seja na perspectiva variacionista, seja na pesquisa dialetológica. Os trabalhos mencionados neste artigo ratificam tal afirmação. Assim, pois, é uma regra que se distribui por todo o Brasil, estando mais presente em uns estados do que em outros.

O que se apresenta de novo neste estudo, algo ainda não contemplado em qualquer estudo anterior, é a comparação entre dados coletados em tempo aparente com dados coletados em tempo real na comunidade de João Pessoa, configurando o que Labov (1994) denomina de estudo de painel. Com esse objetivo em mente, e partindo da hipótese de que, após uma geração, pode-se observar se houve ou não mudança, foram analisados dados de cinco informantes. $\mathrm{O}$ que se constata é que houve mudança nos resultados ao serem confrontados os dados obtidos nas duas amostras, e que a forma palatalizada das oclusivas dentais corresponde ao que a literatura já preconiza, ou seja, é a tendência natural da língua. Portanto, este estudo demonstra que, em geral, há evidências estatísticas de que houve uma real e significativa diferença na fala dos cinco participantes da pesquisa nas entrevistas coletadas em 1993 e 2015, conforme os testes de qui-quadrado, apesar do leve aumento no uso da africada por parte dos participantes. 
Como o foco deste artigo foi nas diferenças individuais e entre as amostras, as variáveis sociais e linguísticas não foram contempladas. No entanto, elas já foram transcritas, codificadas e analisadas, e serão em breve investigadas em estudos futuros.

\section{REFERÊNCIAS}

ABAURRE, M. B. M.; PAGOTTO, E. G. A palatalização das oclusivas dentais no português do Brasil. In: Gramática do português falado VII: novos estudos descritivos. Campinas: Editora da Unicamp, 2002. p. 557-602.

ALMEIDA, M. A. B. de. A variação das oclusivas dentais na comunidade bilíngüe de Flores da Cunha: uma análise quantitativa. 2000. 106 f. Dissertação (Mestrado em Letras - Lingüística Aplicada) - PUCRS, Porto Alegre.

ANDRADE, E. J. B. de. Assimilação como gatilho para a palatalização das oclusivas dentais /t,d/. João Pessoa: UFPB, 2008. Dissertação (Mestrado em Linguística), Universidade Federal da Paraíba, João Pessoa, 2008.

AMORIM, A.; NASCIMENTO, I. C.; HENRIQUE, P; HORA, D. F .L. O efeito do estilo na palatalização das oclusivas dentais. Prolíngua, v. 14, n. 1, 2019.

BATEMAN, N. A crosslinguistic investigation of palatalization. Tese (Doctoral dissertation), University of California, San Diego, 2007.

BATTISTI, E; ROSA, R. S. Variação e mudança linguística: análise em tempo real da palatalização das oclusivas alveolares em um falar do Rio Grande do Sul. Sociodialeto, Campo Grande, v. 2, n. 2, 2012.

BATTISTI, E; FILHO, A. A. D. Análise em tempo real da palatalização de $/ \mathrm{t} / \mathrm{e} / \mathrm{d} / \mathrm{no}$ português falado em uma comunidade ítalo-brasileira. Revista da Abralin, v.14, n.1, 2015. 
BHAT, D. N. S. A general study of palatalization. In: GREENBERG, J. H. (ed.) Universals of Human Language, vol. 2, p. 47-91. Stanford, CA: Stanford University Press. 1978.

BISOL, L. A palatalização e sua restrição variável. Estudos Linguísticos, Salvador, n. 5, p. 163-177, 1985.

CAMARA Jr., J. M. História da linguística. [Tradução de Maria do Amparo Barbosa de Azevedo]. Petrópolis: Vozes, 1976.

CARDOSO, S. A. M. da S. et al. Atlas Linguístico do Brasil. Londrina: Eduel, 2014.

DUTRA, E. O. A palatalização das oclusivas dentais /t/ e /d/ no município do Chuí, Rio Grande do Sul. 130 f. Dissertação (Mestrado em linguística Aplicada) - Faculdade de Letras, Pontifícia universidade Católica do Rio Grande do Sul, 2007.

HELLWIG, B.; GEERTS, J. ELAN - Linguistic Annotator. Versão 4.4.0. Disponível em: http://www.mpi.nl/corpus/manuals/manual-elan.pdf. Acessado em: 10 abr. 2019.

HENRIQUE, P. F. de L.; HORA, D. da. Um olhar sobre a palatalização das oclusivas dentais no vernáculo pessoense. In: Jornada do Grupo de Estudos Linguísticos do Nordeste - GELNE, 24, 2012, Natal, RN. Anais (on-line).

HORA, D. Palatalização das oclusivas dentais: variação e representação não linear. Tese de Doutorado, PUC-RS, 1990.

HORA, D. Projeto Variação Linguística no Estado da Paraíba (VALPB), 1993.

HORA, D. A palatalização das oclusivas dentais /t/ $e$ /d/ e as restrições sociais. Graphos, v. 2, n. 1, p. 116-125, 1997.

HORA, D. Projeto Variação Linguística no Estado da Paraíba: Fase III, 2013. 
KAMIANECKY, F. A palatalização das oclusivas dentais /t/ e /d/ nas comunidades de Porto Alegre e Florianópolis: uma análise quantitativa. Dissertação (Mestrado em Linguística Aplicada) - Faculdade de Letras, Pontifícia Universidade Católica do Rio Grande do Sul, Porto Alegre, 2002.

KOCHETOV, A. Palatalization. In: EWEN, C.; HUME, E.; OOSTENDORP, M. V.; RICE, K. (eds.) Blackwell Companion to Phonology, Oxford: Wiley Blackwell. p. 1666-1690, 2011.

LABOV, W. Principles of linguistic change: internal factors. Vol. 1. Oxford: Blackwell, 1994.

LOPEZ, B. S. The sound partner of brazilian portuguese (Cariocan dialet). Los Angeles: UCLA, 1979. Tese (Doutorado em Linguística), UCLA, 1979.

MATTÉ, G. D. A palatalização variável de / $t$ d / em Caxias do Sul (RS). Livro de Resumos / X XI Salão de Iniciação Científica, XVIII Feira de Iniciação Científica da UFRGS, IV Salão UFRGS Jovem. CD ROM. Porto Alegre: UFRGS, 2009.

PAGOTTO, E. G. Variação e identidade. Tese de Doutorado. Universidade Estadual de Campinas. Programa de Pós-Graduação em Linguística. 2001.

PIRES, L. B. A palatalização das oclusivas dentais /t/ e /d/ em São Borja, RS. Porto Alegre: PUCRS, 2003. Dissertação (Mestrado em Linguística Aplicada), Faculdade de Letras, Pontifícia Universidade Católica do Rio Grande do Sul, 2003.

R CORE TEAM. R: A language and environment for statistical computing. $\mathrm{R}$ Foundation for Statistical Computing, Vienna, Austria, 2019.

RSTUDIO TEAM. RStudio: Integrated Development Environment for R. Boston, MA, 2018. URL: <http://www.rstudio.com/>. 
SANTOS, L. de F. Realização das oclusivas dentais /t/ e /d/ na fala de Maceió. Alagoas: UFAL, 1996.

SCHILLING-ESTES, Natalie. Language change in apparent and real time: The Community and the individual. University of Pennsylvania Working Papers in Linguistics, v. 10, n. 2, p. 17, 2005.

SILVA FILHO, E. B. Oclusivas alveolares e africadas alveopalatais no português de Recife. 144 f. Tese (Doutorado em Letras) - Universidade Federal de Pernambuco. Recife, 2018.

WEINREICH, U.; LABOV, W.; HERZOG, M. Fundamentos empíricos para uma teoria da mudança linguística. Trad.: Marcos Bagno; revisão técnica: Carlos Alberto Faraco. São Paulo: Parábola, 2006. 